\title{
Densidade de minicepas em minijardim clonal na produção de mudas de eucalipto
}

\author{
Cibele Chaves Souza ${ }^{1}$, Aloisio Xavier ${ }^{1}$, Fernando Palha Leite ${ }^{2}$, Reynaldo Campos Santana ${ }^{3}$, Haroldo Nogueira de Paiva ${ }^{1}$ \\ ${ }^{1}$ Universidade Federal de Viçosa, Departamento de Engenharia Florestal, Avenida PH Rolfs, s/nº, CEP 36571-000, Viçosa, MG, Brasil \\ ${ }^{2}$ Celulose Nipo Brasileira SA, Coordenação de Pesquisa e Desenvolvimento Florestal, Rodovia MG 758, km 3, s/nº, CP 100, CEP 35195-000, Belo Oriente, MG, Brasil \\ ${ }^{3}$ Universidade Federal dos Vales do Jequitinhonha e Mucuri, Departamento de Engenharia Florestal, Rod. MG 367, n 5.000, Campus JK, BI 5, CEP 39100-000, \\ Diamantina, MG, Brasil
}

"Autor correspondente:
souza.cc24@hotmail.com

Termos para indexação:

Miniestaquia

Propagação vegetativa

Silvicultura clonal

Index terms:

Mini-cutting technique

Vegetative propagation

Clonal forestry

Histórico do artigo:

Recebido em 17/04/2013

Aprovado em 26/03/2014

Publicado em 04/04/2014

doi: 10.4336/2014.pfb.34.77.512
Resumo - O objetivo deste trabalho foi avaliar diferentes densidades de minicepas quanto à produtividade e sobrevivência bem como os efeitos na produção e sobrevivência das miniestacas produzidas. Foram realizados dois experimentos distintos, um para cada material genético $(\mathrm{C} 1$ e $\mathrm{C} 2)$ e foram avaliadas três densidades para o clone $\mathrm{C} 1$ $\left(88,75\right.$ e 57 minicepas $\left.\mathrm{m}^{-2}\right)$ e duas para o clone $\mathrm{C} 2$ (104 e 78 minicepas $\left.\mathrm{m}^{-2}\right)$. Foram coletadas brotações das minicepas, utilizadas na confecção de miniestacas de 6 a 10 $\mathrm{cm}$ de comprimento. As coletas foram iniciadas em janeiro de 2011, encerrando-se em março de 2011. As miniestacas foram plantadas em substrato composto por $50 \%$ de vermiculita e $50 \%$ de casca de arroz carbonizada sendo posteriormente conduzidas às seguintes etapas: casa de vegetação, casa de sombra e área de rustificação. Para os dois clones, a densidade com menor número de minicepas $\mathrm{m}^{-2}$ resultou em menor taxa de mortalidade das minicepas e maior produção de miniestacas por minicepa. A sobrevivência das miniestacas na primeira seleção (após a saída da casa de sombra) e das mudas na segunda seleção (50 dias após o plantio) não foi afetada pelo espaçamento utilizado para as minicepas.

\section{Density mini-stumps on mini-clonal hedge in the production of clonal seedlings eucalyptus}

\begin{abstract}
The objective of this work was to evaluate different densities of rooted productivity and survival as well as the effects on production and survival of cuttings produced. We performed two separate experiments, one for each genetic material $(\mathrm{Cl}$ and $\mathrm{C} 2)$ and were assessed three densities for clone $\mathrm{C} 1\left(88,75\right.$ and 57 ministumps $\left.\mathrm{m}^{-2}\right)$ and two for clone $\mathrm{C} 2$ ( 104 and 78 ministumps $\mathrm{m}^{-2}$ ). Shoots we collected from the ministumps and they were used in making cuttings $6-10 \mathrm{~cm}$ long. Sampling was initiated in January 2011, ending in March 2011. The cuttings were planted in substrate composed of 50\% vermiculite and $50 \%$ of rice hulls and subsequently they were conducted in following steps: greenhouse, shade house and field hardening. For both clones, the density with smaller number of mini-stumps $\mathrm{m}^{-2}$ resulted in lower mortality rate of mini-stumps and higher production of mini-cuttings. The survival of mini-cuttings in the first selection (when exiting from the shade) and the second selection of seedlings (50 days after planting) was not affected by the spacing given the mini-stumps.
\end{abstract}




\section{Introdução}

Com a evolução do jardim clonal em campo para o minijardim clonal em viveiro, conseguiu-se uma redução significativa de área para coleta de estacas, partindo de um espaçamento de $3 \mathrm{~m} \times 3 \mathrm{~m}$ em campo para $0,1 \mathrm{~m}$ x 0,1 m em sistema semi-hidropônico em viveiro. Com o minijardim clonal é possível obter maior frequência de coleta, redução do tamanho da estaca e aumento da produtividade (Higashi et al., 2000), a qual pode ser influenciada pelas variáveis climáticas, pelo material genético (Cunha et al., 2009), pelo sistema de produção (semi-hidropônico em canaletas de areia ou tubete) (Cunha et al., 2005), pela nutrição mineral (Higashi \& Silveira, 2002), pelo manejo das mudas que compõem o minijardim (Mafia et al., 2005), entre outros.

Os minijardins clonais podem ser formados pela condução das minicepas diretamente em tubetes, em tubos de PVC, em vasos diversos ou, em sua grande maioria, por canaletas de alvenaria, preenchidas com brita no fundo e areia lavada até a borda, formando um sistema semi-hidropônico. A formação do minijardim clonal se dá por meio do enraizamento de miniestacas provenientes das brotações de plantas propagadas pelo método da estaquia convencional ou até mesmo pelo método de miniestaquia. As miniestacas enraizadas têm seus ápices podados na altura de $10 \mathrm{~cm}$, constituindo, assim, as minicepas que fornecerão as brotações (miniestacas) (Higashi et al., 2000; Higashi \& Silveira, 2002; Souza Junior \& Wendling, 2003; Alfenas et al., 2009; Xavier et al., 2013).

Encontram-se na literatura inúmeros trabalhos relacionados a minijardins clonais de Eucalyptus spp. (Higashi et al., 2002; Souza Junior \& Wendling, 2003; Cunha et al., 2005; Mafia et al., 2005; Cunha et al., 2009). No entanto, trabalhos relacionando a densidade de minicepas em canaletas e a produção de miniestacas são realizados empiricamente por empresas do setor florestal, sem rigor científico.

Higashi et al. (2000) mostraram que um minijardim clonal, com espaçamento reduzido, tem maior produção do que um jardim clonal com espaçamento normal. No entanto, não se sabe até que ponto a redução do espaçamento afeta a produção e a sobrevivência das minicepas. Nesse contexto, o presente trabalho tem por objetivo avaliar diferentes densidades de minicepas, bem como os efeitos na produção e sobrevivência das miniestacas produzidas.

\section{Material e métodos}

O trabalho foi realizado no período de janeiro a março de 2011, no viveiro florestal da empresa Celulose Nipo-brasileiro S.A. (Cenibra), localizada no Município de Belo Oriente $\left(19^{\circ} 18^{\prime} 23^{\prime}\right.$ 'S e $\left.42^{\circ} 22^{\prime} 46^{\prime \prime} \mathrm{O}\right)$, MG. O clima dessa região é do tipo Cwa (subtropical, chuvoso e mesotérmico), segundo a classificação de Köppen, e a altitude média é de $240 \mathrm{~m}$. A precipitação do período de realização do trabalho foi de $106,0 \mathrm{~mm}$, temperatura média de $25,2^{\circ} \mathrm{C}$, com máxima média do período de $34,5{ }^{\circ} \mathrm{C}$, mínima de $19,0{ }^{\circ} \mathrm{C}$, e umidade relativa do ar média do período de $76,6 \%$.

Foram utilizados dois materiais genéticos, constituídos pelos clones: C1 - Eucalyptus grandis x E. urophylla e C2 - Eucalyptus grandis. $\mathrm{Na}$ data de implantação dos canaletões de areia, para o clone $\mathrm{C} 1$, foram utilizadas as densidades iniciais de plantio de 125,100 e 84 minicepas $\mathrm{m}^{-2}$, correspondendo aos espaçamentos iniciais de " 0,08 x $0,10 \mathrm{~m}$ "; " 0,10 x $0,10 \mathrm{~m}$ " e " 0,10 x 0,12 m". Para o clone $\mathrm{C} 2$, foram testadas densidades iniciais de plantio de 125 minicepas $\mathrm{m}^{-2}$ e 84 minicepas $\mathrm{m}^{-2}$, sendo a primeira canaleta implantada com oito fileiras de minicepas, espaçadas de $0,10 \mathrm{~m}$, perfazendo 8 fileiras no sentido longitudinal com espaçamento de $0,10 \times 0,08 \mathrm{~m}$, e a segunda canaleta foi implantada eliminando-se duas fileiras, ficando com seis fileiras de minicepas no sentido longitudinal.

Em virtude da mortalidade de minicepas em relação à data de implantação dos canaletões e a data inicial da pesquisa, foram consideradas as densidades para tratamentos iniciais de 88,75 e 57 minicepas $\mathrm{m}^{-2}$ para o clone $\mathrm{C} 1$; e de 104 e 78 miniestacas $\mathrm{m}^{-2}$ para o clone C2 (Tabela 1).

Tabela 1. Data de plantio das minicepas nos canaletões, densidade inicial de minicepas e densidade utilizada para os experimentos com os clones $\mathrm{C} 1$ e $\mathrm{C} 2$.

\begin{tabular}{|c|c|c|}
\hline Clone & $\begin{array}{l}\text { Densidade inicial } \\
\text { na implantação } \\
(\text { minicepas m²) }\end{array}$ & $\begin{array}{c}\text { Densidade existente } \\
\text { no início da } \\
\text { experimentação } \\
\left(\text { minicepas } \mathbf{m}^{-2}\right)\end{array}$ \\
\hline \multirow{4}{*}{$\mathrm{C1}$} & (março de 2010) & (janeiro de 2011) \\
\hline & 125 & 88 \\
\hline & 100 & 75 \\
\hline & 84 & 57 \\
\hline \multirow{2}{*}{$\mathrm{C} 2$} & 125 & 104 \\
\hline & 84 & 78 \\
\hline
\end{tabular}


As miniestacas foram coletadas em minijardim clonal, instalado nos espaçamentos testados por meio do enraizamento de miniestacas provenientes das brotações de plantas propagadas por miniestaquia. As miniestacas enraizadas tiveram seus ápices podados na altura de
$10 \mathrm{~cm}$, constituindo, assim, as minicepas, que forneceram as brotações (miniestacas). O minijardim clonal foi constituído por canaletas de alvenaria, preenchidas com brita no fundo e areia lavada até a borda (Figura 1).
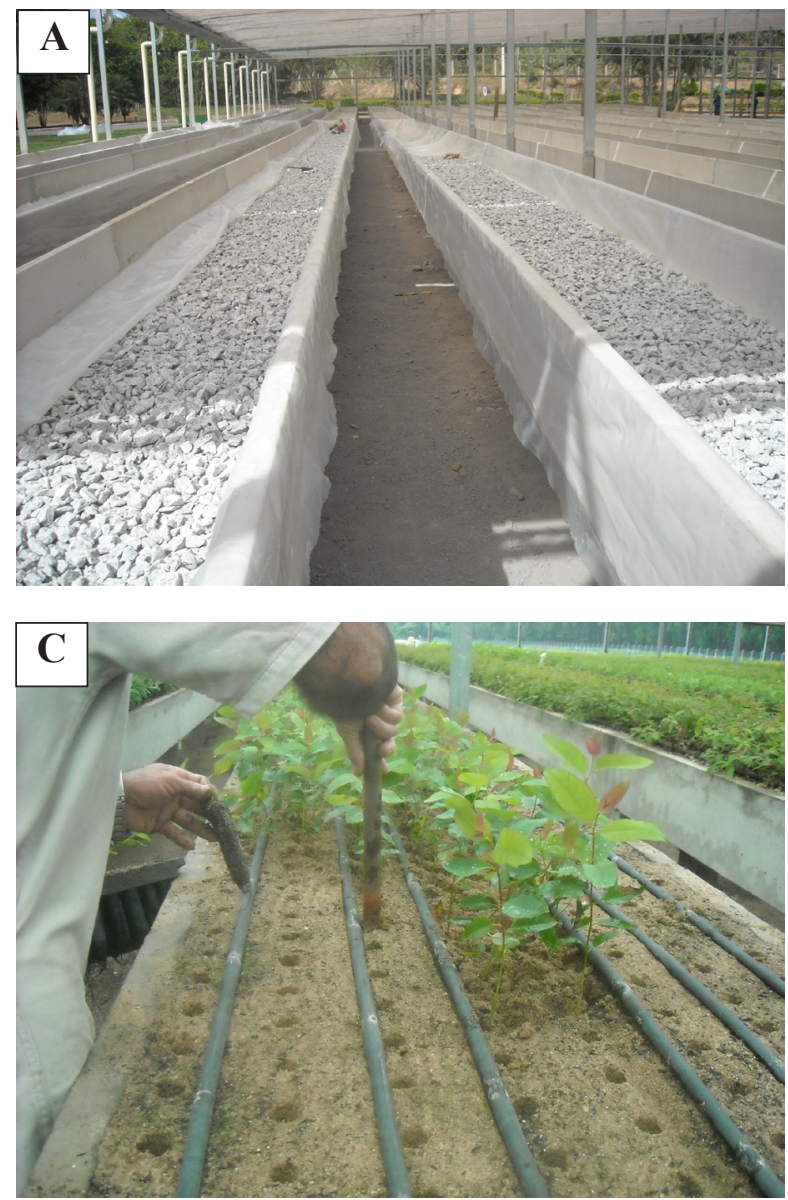
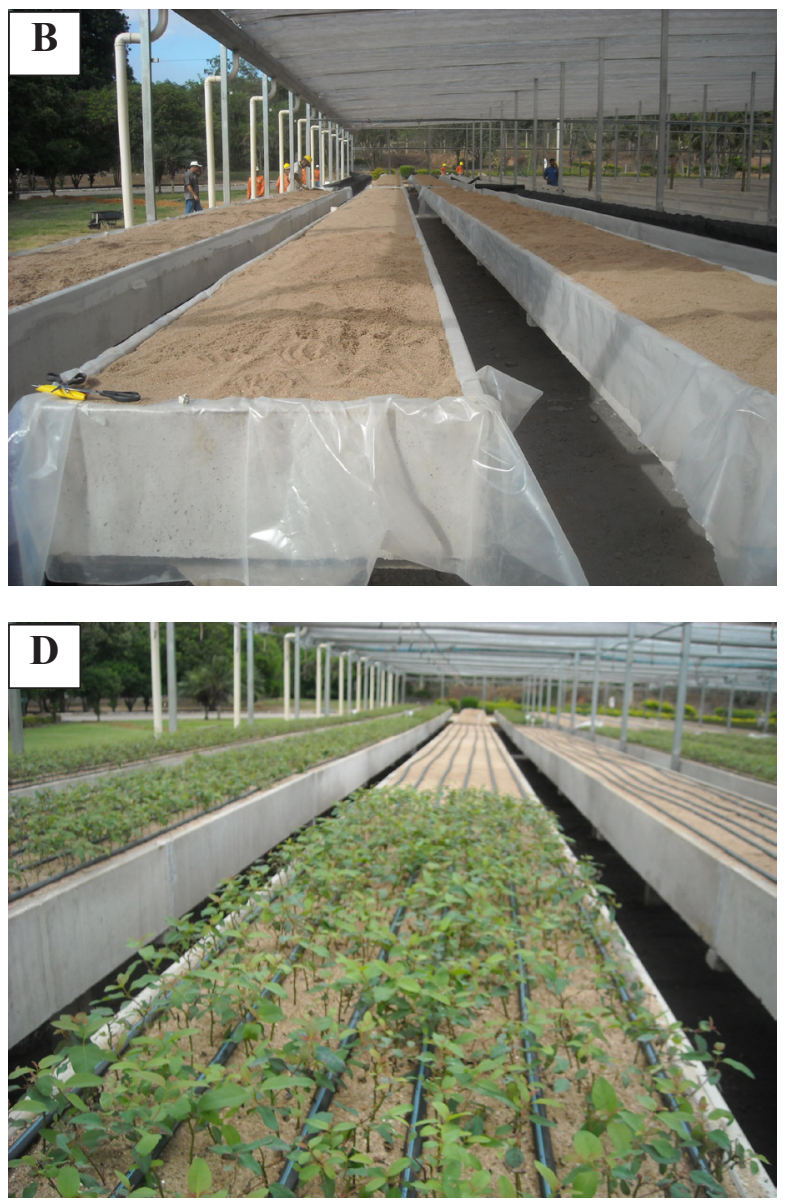

Figura 1. Canaletão de alvenaria onde foram instalados os experimentos (A e B) e plantio das mudas no canaletão (C e D).

A irrigação e fertilização mineral do minijardim clonal foram feitas utilizando um sistema automatizado de fertirrigação por gotejamento, acionado 3 a 4 vezes por dia, de acordo com a temperatura do dia, variando de 0 em dias frios a $7 \mathrm{~mm} \mathrm{~m}^{-2}$ dia $^{-1}$ em dias muito quentes, por um período de 6 min. A solução nutritiva foi composta por nitrato de cálcio $\left(0,92 \mathrm{~g} \mathrm{~L}^{-1}\right)$, cloreto de potássio $\left(0,24 \mathrm{~g} \mathrm{~L}^{-1}\right)$, nitrato de potássio $\left(0,14 \mathrm{~g} \mathrm{~L}^{-1}\right)$, fosfato monoamônio $\left(0,10 \mathrm{~g} \mathrm{~L}^{-1}\right)$, sulfato de magnésio $\left(0,36 \mathrm{~g} \mathrm{~L}^{-1}\right)$, hidroferro $\left(0,04 \mathrm{~g} \mathrm{~L}^{-1}\right)$, ácido bórico $\left(2,80 \mathrm{mg} \mathrm{L}^{-1}\right)$, sulfato de zinco $\left(0,48 \mathrm{mg} \mathrm{L}^{-1}\right)$, sulfato de manganês $\left(1,12 \mathrm{mg} \mathrm{L}^{-1}\right)$, sulfato de cobre $\left(0,10 \mathrm{mg} \mathrm{L}^{-1}\right)$ e molibdato de sódio $\left(0,04 \mathrm{mg} \mathrm{L}^{-1}\right)$. O excesso da solução nutritiva foi drenado para o fundo da canaleta e retornava, por meio de um sistema de tubulações, para a caixa de armazenamento da solução, monitorada regularmente e trocada a cada sete dias. Diariamente, foram monitorados a condutividade elétrica $(\mathrm{Ec})$ e o $\mathrm{pH}$ da solução, visando manter a Ec entre 1,0 e $1,5 \mathrm{mS} \mathrm{cm}^{-1}$ e o pH da solução entre 5,5 e 6,5.

Em períodos variáveis, de acordo com o vigor das minicepas, coletaram-se brotações, utilizadas na confecção de miniestacas de 6 a $10 \mathrm{~cm}$ de comprimento. As coletas foram iniciadas em janeiro de 2011, tendo sido realizadas 9 coletas para o clone $\mathrm{C} 1$ e 10 coletas para o clone $\mathrm{C} 2$, encerrando-se em março de 2011. 
Após a coleta, as miniestacas foram estaqueadas em tubetes de plástico rígido com $12 \mathrm{~cm}$ de comprimento e $55 \mathrm{~cm}^{3}$ de capacidade, previamente desinfestados em água quente a $70{ }^{\circ} \mathrm{C}$ por $1 \mathrm{~min}$. O substrato utilizado foi composto por $50 \%$ de vermiculita e $50 \%$ de casca de arroz carbonizada. A formulação de adubação adotada foi constituída de $7,0 \mathrm{~kg} \mathrm{~m}^{-3}$ de superfosfato simples, $0,695 \mathrm{~kg} \mathrm{~m}^{-3}$ de sulfato de amônio, 0,208 $\mathrm{kg} \mathrm{m}^{-3}$ de cloreto de potássio, $0,014 \mathrm{~kg} \mathrm{~m}^{-3}$ de sulfato de zinco, $0,014 \mathrm{~kg} \mathrm{~m}^{-3}$ de sulfato de cobre, $0,0140 \mathrm{~kg} \mathrm{~m}^{-3}$ de sulfato de manganês e $0,021 \mathrm{~kg} \mathrm{~m}^{-3}$ de ácido bórico.

Após o estaqueamento, as miniestacas foram levadas para a casa de vegetação climatizada (umidade relativa do ar $\geq 80 \%$ e temperatura entre 20 e $30{ }^{\circ} \mathrm{C}$ ) para enraizamento, onde permaneceram por 20 dias. Posteriormente, foram aclimatadas em casa de sombra com $50 \%$ de sombreamento, durante 10 dias. Na saída da casa de sombra, as miniestacas passaram por uma seleção em que se observou o tamanho, o enraizamento e a sobrevivência das mudas. Nessa etapa, as mudas foram agrupadas em duas classes de tamanho e posteriormente transferidas para bandejas, de modo a preencher $40 \%$ da capacidade destas bandejas, processo esse chamado de primeira seleção. As bandejas com as mudas foram transferidas para a área a pleno sol, onde permaneceram por cerca de 20 dias, até completarem 50 dias de idade. Após essa etapa, as mudas foram submetidas à segunda seleção, processo semelhante à primeira, quando também foram retiradas as brotações laterais das mudas.

\section{Delineamento experimental, avaliações e análises estatísticas}

Foram realizados experimentos distintos para cada clone (C1 e $\mathrm{C} 2$ ). Para ambos, o delineamento experimental utilizado foi o inteiramente casualizado, composto de cinco repetições de um metro quadrado por tratamento. Para o clone $\mathrm{C} 1$, foram utilizados 3 espaçamentos e para o clone $\mathrm{C} 2$, dois espaçamentos. A coleta mensal correspondeu à soma de três coletas, com exceção do mês de janeiro para o clone $\mathrm{C} 2$, que teve quatro coletas. Para efeito de análise estatística, foram avaliados a produção média mensal de miniestacas por metro quadrado e os valores médios do total das coletas dos tratamentos.

Foram avaliadas a produção de miniestacas por metro quadrado (PMEM2), a produção de miniestacas por minicepas (PMEMC), sobrevivência das minicepas por metro quadrado (SMM2), sobrevivência das miniestacas na primeira seleção (SOBME1) (após a saída da casa de sombra - 30 dias após o estaqueamento) e das mudas na segunda seleção (SOBMU2) (50 dias após o estaqueamento).

Para o cálculo de produção de miniestacas por minicepas (PMEMC), foi considerado o número de minicepas vivas a cada mês. Para o cálculo da sobrevivência das minicepas por metro quadrado (SMM2), foi considerada a densidade de plantio inicial nos canaletões.

Os dados foram submetidos à análise de variância e, quando pertinente, foi realizado o teste de Tukey a 5\% de probabilidade.

\section{Resultados e discussão}

O número de minicepas vivas para cada clone está apresentado na Tabela 2,

De acordo com os resultados obtidos para o clone $\mathrm{C} 1$, observou-se efeito significativo $(\mathrm{P}<0,05)$ entre as médias dos tratamentos das densidades das minicepas para quase todas as características avaliadas, exceto para a sobrevivência das miniestacas na primeira seleção (SOBME1) e das mudas na segunda seleção (SOBMU2) (Figura 1).

Tabela 2. Sobrevivência das minicepas dos clones $\mathrm{C} 1$ e C2, para cada tratamento implantado nos canaletões em cada mês de avaliação.

\begin{tabular}{ccccc}
\hline \multirow{2}{*}{ Clone } & $\begin{array}{c}\text { Tratamentos } \\
\left(\text { minicepas } \text { m }^{-2}\right)\end{array}$ & Janeiro & $\begin{array}{c}\text { Fevereiro } \\
\left(\text { minicepas m } \mathbf{~ m}^{-2}\right)\end{array}$ & Março \\
\cline { 3 - 5 } & 88 & 88 & 72 & 67 \\
\multirow{3}{*}{ C1 } & 75 & 75 & 69 & 66 \\
& 57 & 57 & 54 & 51 \\
\hline \multirow{2}{*}{ C2 } & 104 & 104 & 101 & 99 \\
& 78 & 78 & 75 & 77 \\
\hline
\end{tabular}

A produção média mensal de miniestacas $\mathrm{m}^{-2}$ (Figura 1A) foi maior para a menor densidade. Para o menor espaçamento (densidade de 88 minicepas $\mathrm{m}^{-2}$ ) a produção foi decrescendo ao passar dos meses, o que não ocorreu para os demais espaçamentos avaliados. Observou-se que a produção por minicepa no espaçamento com 57 minicepas $\mathrm{m}^{-2}$ foi superior aos demais, alcançando 12,6 miniestacas/minicepa no mês de março (Figura 1B).

Para o clone $\mathrm{C} 1$, não foi observada redução da produção no decorrer das coletas, demonstrando a não- 
exaustão das minicepas durante o período de avaliação (Wendling et al., 2000), conseguindo até aumentar, significativamente, a produção para o espaçamento com 84 minicepas $\mathrm{m}^{-2}$. O aumento da produção de miniestacas

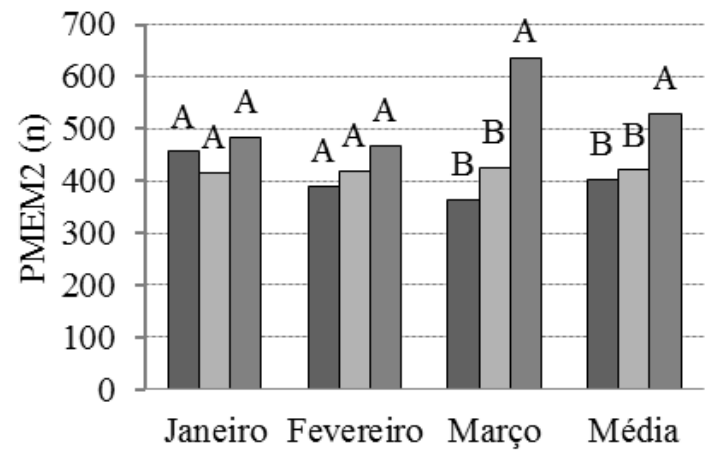

(A)

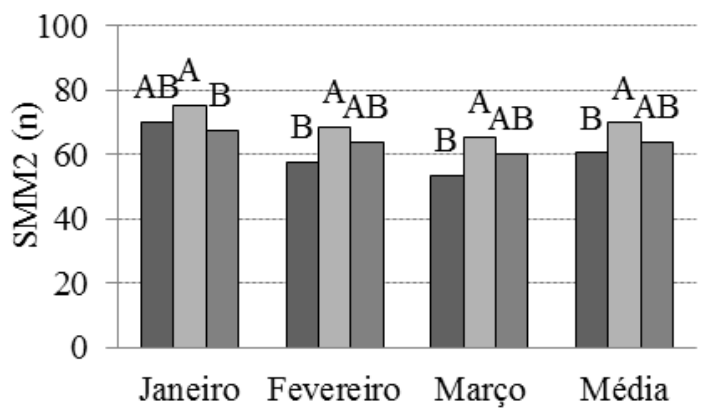

(C)

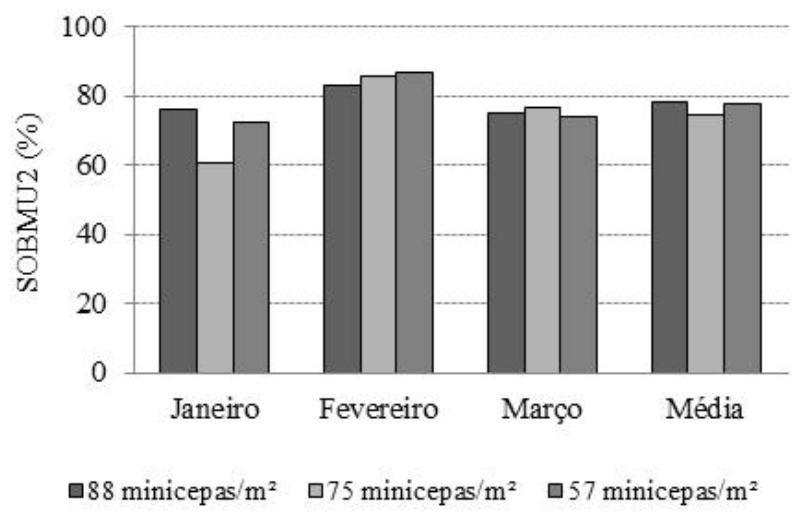

por coleta também foi relatado para outras espécies de Eucalyptus como E. grandis (Titon et al., 2003b), E. dunni (Souza Junior \& Wendling, 2003; Rosa et al., 2009) e E. benthamii (Cunha et al., 2005).

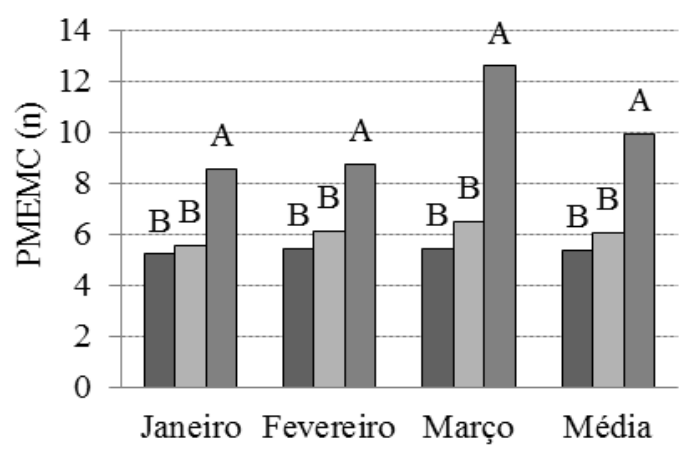

(B)

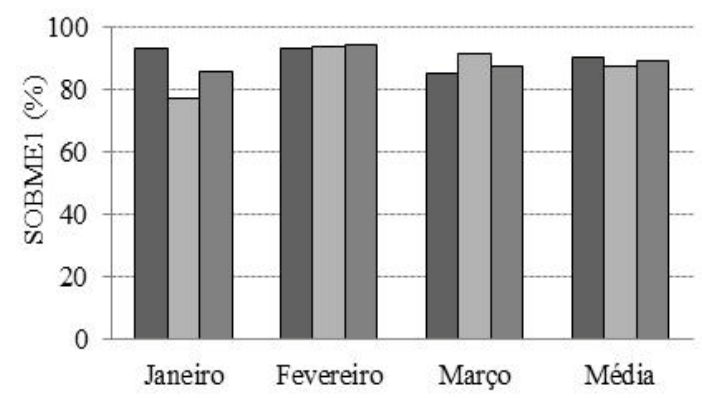

(D)

(E)

Figura 1. Valores médios da produção de miniestacas $\mathrm{m}^{-2}$ (PMEM2), produção de miniestacas por minicepas (PMEMC), sobrevivência das minicepas $\mathrm{m}^{-2}$ (SMM2), sobrevivência das miniestacas na primeira seleção (SOBME1) e sobrevivência das mudas na segunda seleção (SOBME2) do clone C1 (híbrido de Eucalyptus grandis x E. urophylla), em função de três densidades de minicepas no minijardim clonal em três meses de coleta. Médias seguidas de uma mesma letra para o mesmo mês de coleta, não diferem entre si, pelo teste de Tukey a $5 \%$ de probabilidade. 
$\mathrm{O}$ fato de a produtividade das menores densidades de minicepas $\mathrm{m}^{-2}$ ser maior para o clone $\mathrm{C} 1$ e praticamente semelhante para o clone $\mathrm{C} 2$ pode estar relacionado a menor competição por luz, água, nutrientes e espaçamentos entre as minicepas. Com menor número de minicepas $\mathrm{m}^{-2}$ consegue-se uma distribuição mais homogênea da radiação fotossinteticamente ativa entre as folhas, conseguindo, assim, um aumento da produção por miniestaca, uma vez que a luz influencia positivamente a produtividade das minicepas (Cunha et al., 2009).

A nutrição exerce influência sobre a produção de miniestacas (Higashi et al., 2002), no entanto, a nutrição nas canaletas foi a mesma para todos os espaçamentos. Os maiores espaçamentos proporcionaram produção média superior à encontrada por Cunha et al. (2009), que, estudando produção de mudas clonais de híbridos de Eucalyptus spp., encontraram produção média de 9,2 miniestacas/minicepa, considerando uma densidade inicial de 125 minicepas $\mathrm{m}^{-2}$.

Quanto à sobrevivência das minicepas, ocorreu uma queda mais acentuada para a densidade de 88 minicepas $\mathrm{m}^{-2}$, representando uma redução de cerca de $24 \%$ de janeiro a março. Para as densidades iniciais com 100 e 84 minicepas $^{-2}$ (tratamentos com 75 e 57 minicepas $\mathrm{m}^{-2}$ ), respectivamente, houve apenas uma redução de $13 \%$ e $11 \%$, respectivamente, para o mesmo período. Quando se utiliza menor número de mudas $\mathrm{m}^{-2}$ para compor o minijardim clonal, tem-se o menor gasto com mudas para montagem do minijardim e também com a substituição das mudas mortas, já que foi observada uma menor mortalidade das minicepas nos maiores espaçamentos, principalmente para o clone $\mathrm{C} 1$ (Figura 1C).

Observou-se que a produção de miniestacas por minicepas seguiu uma tendência inversa à sobrevivência das minicepas, ou seja, com a liberação de espaço pelas minicepas mortas, conseguiu-se maior produção pelas remanescentes, concentrando nelas os fatores de crescimento.

A sobrevivência das miniestacas na primeira seleção e das mudas na segunda seleção seguiu a mesma tendência, apresentando melhores resultados no mês de fevereiro (Figuras 1D e 1E). No mês de janeiro, a densidade de 75 minicepas $\mathrm{m}^{-2}$ teve menores resultados, já em março este tratamento apresentou os maiores índices de sobrevivência. A sobrevivência na primeira seleção foi, em média, de $89 \%$ e na segunda $76 \%$.

A sobrevivência das miniestacas na primeira seleção variou de acordo com os meses de coleta e não foi regular entre os espaçamentos para o clone $\mathrm{C} 1$, mostrando que o espaçamento, em termos gerais, não influenciou o vigor das miniestacas produzidas, não refletindo na sobrevivência final. $\mathrm{O}$ fato de ter apresentado baixa taxa de sobrevivência para a densidade de 75 minicepas $\mathrm{m}^{-2}$ no mês de janeiro, pode estar relacionado a fatores de manejo das mudas no viveiro, ou a algum fato excepcional não ligado ao efeito do espaçamento inicial das minicepas. Dentre vários fatores que podem ter influenciado no enraizamento e em consequência na sobrevivência das mudas provenientes desse espaçamento, pode-se citar o excesso ou falta de água no substrato utilizado para o enriquecimento, coleta diferenciada e vigor das miniestacas coletadas (Alfenas et al., 2009; Xavier et al., 2013).

Outros fatores ambientais podem ter contribuído para a redução nos percentuais de sobrevivência das miniestacas na primeira seleção, nos quais podemos citar a falta de um controle mais rigoroso da luminosidade e fotoperíodo na casa de vegetação, o aquecimento do substrato (Higashi et al., 2000) e condições de transporte e armazenamento das miniestacas que, de acordo com Goulart \& Xavier (2008), deve ser plantada logo após a coleta no minijardim clonal. Como o experimento foi realizado em época de verão, com temperaturas altas, pode ter favorecido a transpiração excessiva das miniestacas, devido ao horário de coleta e pelos fatores citados anteriormente.

Titon et al. (2003a) encontraram valores médios de cerca de $85 \%$ para sobrevivência de miniestacas na saída da casa de sombra e cerca de $78 \%$ aos 50 dias após o estaqueamento, valores próximos aos encontrados para os dois clones, indicando que o manejo das mudas foi satisfatório.

Para o clone C2, foram estudados somente dois espaçamentos em que se observou efeito significativo $(\mathrm{P}<0,05)$ somente para a produção de miniestacas por minicepa (PMEMC) (Figura 2B).

Para a produção de miniestacas por minicepa, a densidade inicial de 78 minicepas $\mathrm{m}^{-2}$ apresentou maior produção com destaque para o mês de janeiro (Figura 2B).

Não foram observadas diferenças significativas da sobrevivência das mudas produzidas com miniestacas provenientes da densidade de 78 e 104 miniestacas $\mathrm{m}^{-2}$ (Figura 2C). Em média, a taxa de sobrevivência das miniestacas na primeira seleção e das mudas na segunda seleção oscilou em torno de $86 \%$ e $80 \%$ para as densidades de 104 miniestacas $\mathrm{m}^{-2}$ e de $89 \%$ e $83 \%$ para 78 miniestacas $\mathrm{m}^{-2}$, respectivamente (Figuras $2 \mathrm{D}$ e 2E). 


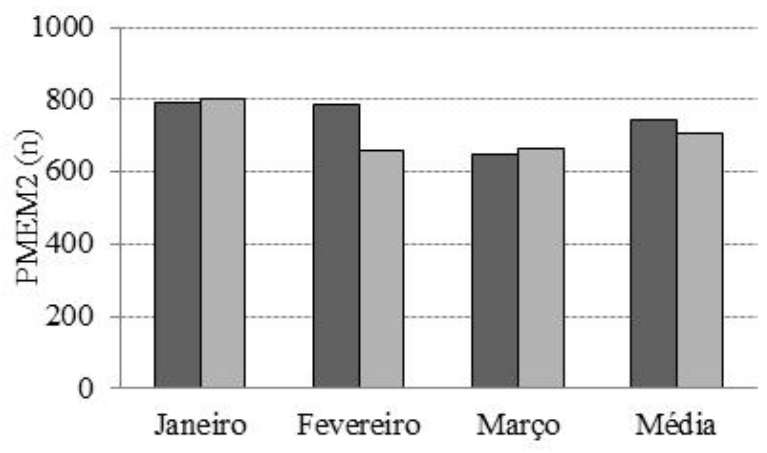

(A)

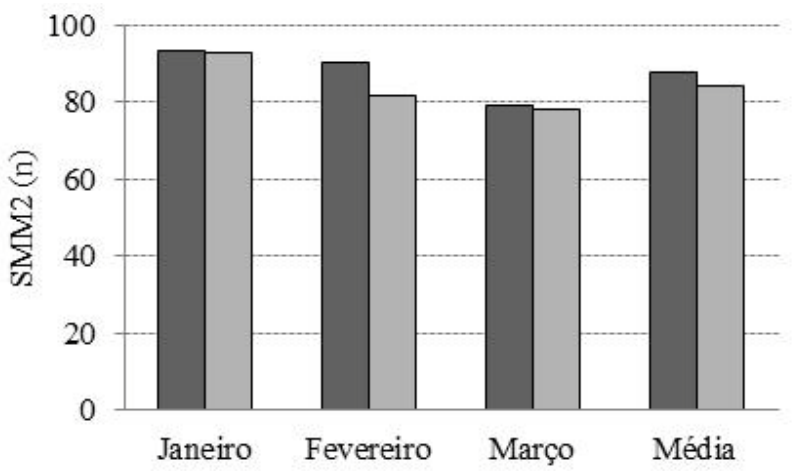

(C)

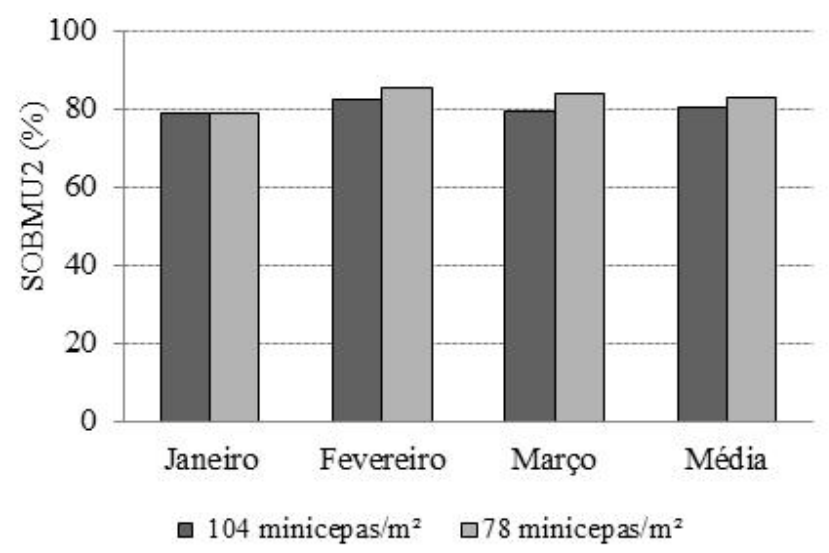

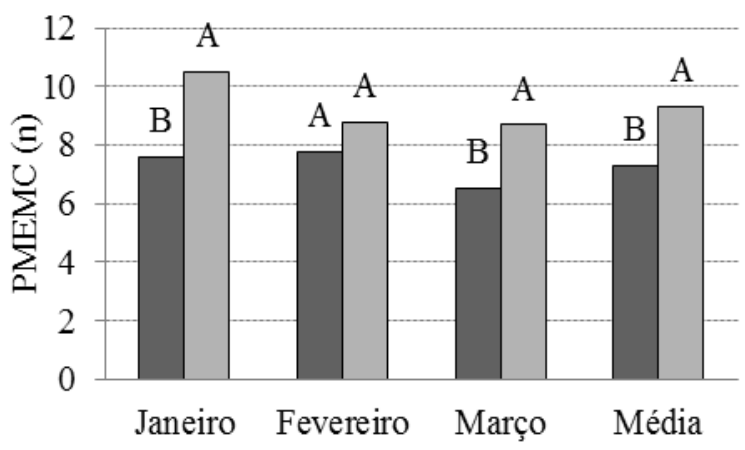

(B)

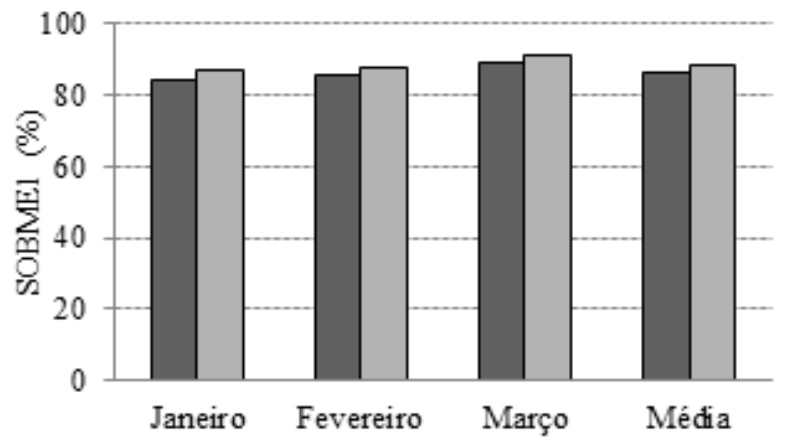

(D)

(E)

Figura 2 - Valores médios da produção de miniestacas $\mathrm{m}^{-2}$ (PMEM2), produção de miniestacas por minicepas (PMEMC), sobrevivência das minicepas $\mathrm{m}^{-2}$ (SMM2), sobrevivência das miniestacas na primeira seleção (SOBME1) e sobrevivência das mudas na segunda seleção (SOBME2) do clone C2, em função de duas densidades de minicepas no minijardim clonal em três meses de coleta. Médias seguidas de uma mesma letra para o mesmo mês de coleta, não diferem entre si, pelo teste de Tukey a $5 \%$ de probabilidade. 


\section{Conclusão}

A densidade com menor número de minicepas $\mathrm{m}^{-2}$ resultou em menor taxa de mortalidade das minicepas e maior produção de miniestacas por minicepa, em relação aos outros utilizados nesse experimento.

A sobrevivência das mudas produzidas a partir das miniestacas não foi afetada pelo espaçamento dado às minicepas.

\section{Agradecimentos}

Ao Conselho Nacional de Desenvolvimento Científico e Tecnológico (CNPq), pela concessão de bolsas de estudo, e à empresa Celulose Nipo-Brasileira S.A. (Cenibra), pelo apoio financeiro e de infraestrutura.

\section{Referências}

ALFENAS, A. C., ZAUZA, E. A. V., MAFIA, R. G., ASSIS, T. F. Clonagem e doenças do eucalipto. Viçosa, MG: Ed da UFV, 2009. $500 \mathrm{p}$

CUNHA, A. C. M. C. M.; WENDLING, I.; SOUZA JÚNIOR, L. Produtividade e sobrevivência de minicepas de Eucalyptus benthamii Maiden et Cambage em sistema de hidroponia e em tubete. Ciência Florestal, Santa Maria, RS, v. 15, n. 3, p. 307-310, 2005.

CUNHA, A. C. M. C. M.; PAIVA, H. N.; LEITE, H. G.; BARROS, N. F.; LEITE, F. P. Relações entre variáveis climáticas com produção e enraizamento de miniestacas de eucalipto. Revista Árvore, Viçosa, MG, v. 33, n. 2, p. 195-203, 2009.

GOULART, P. B.; XAVIER, A. Efeito do tempo de armazenamento de miniestacas no enraizamento de clones de Eucalyptus grandis $\mathrm{x} E$. urophylla. Revista Árvore, Viçosa, MG, v. 32, n. 4, p. 671-677, 2008.
HIGASHI, E. N.; SILVEIRA, R. L. V.; GONÇALVES, A. N. Evolução do jardim clonal de eucalipto para a produção de mudas. IPEF Notícias, Piracicaba, v. 24, n. 148, p. 4-5, 2000.

HIGASHI, E. N.; SILVEIRA, R. L. V. A. Nutrição e adubação em minijardim clonal hidropônico de Eucalyptus. Circular Técnica IPEF, Piracicaba, n. 194, 2002.

MAFIA, R. G.; ALFENAS, A. C.; FERREIRA, E. M.; ZARPELON, T. G.; SIQUEIRA, L. Crescimento de mudas e produtividade de minijardins clonais de eucalipto tratados com rizobactérias selecionadas. Revista Árvore, Viçosa, MG, v. 29, n. 6, p. 843-851, 2005.

ROSA, L. S.; WENDLING, I.; GROSSI, F.; REISSMANN, C. B. Efeito da dose de nitrogênio e de formulações de substratos na miniestaquia de Eucalyptus dunnii MAIDEN. Revista Árvore, Viçosa-MG, v.33, n.6, p.1025-1035, 2009.

SOUZA JUNIOR, L.; WENDLING, I. Propagação vegetativa de Eucalyptus dunnii via miniestaquia de material juvenil. Boletim de Pesquisa Florestal, Colombo, n. 46, p. 21-30, 2003.

TITON, M.; XAVIER, A.; OTONI, W. C.; REIS, G. G. Efeito do AIB no enraizamento de miniestacas e microestacas de clones de Eucalyptus grandis W. Hill ex Maiden. Revista Árvore, Viçosa, MG, v. 27, n. 1, p. 1-7, 2003a.

TITON, M.; XAVIER, A.; REIS, G. G.; OTONI, W. C. Eficiência das minicepas e microcepas na produção de propágulos de clones de Eucalyptus grandis. Revista Árvore, Viçosa, MG, v. 27, n. 5, p. 619-625, 2003b.

WENDLING, I.; XAVIER, A.; GOMES, J. M.; PIRES, I. E.; ANDRADE, H. B. Propagação clonal de híbridos de Eucalyptus spp. por miniestaquia. Revista Árvore, Viçosa, MG, v. 24, n. 2, p. 181-186, 2000.

XAVIER, A.; WENDLING, I.; SILVA, R. L. Silvicultura clonal: princípios e técnicas. 2. ed. Viçosa, MG: Ed. da UFV, 2013. 279 p. 